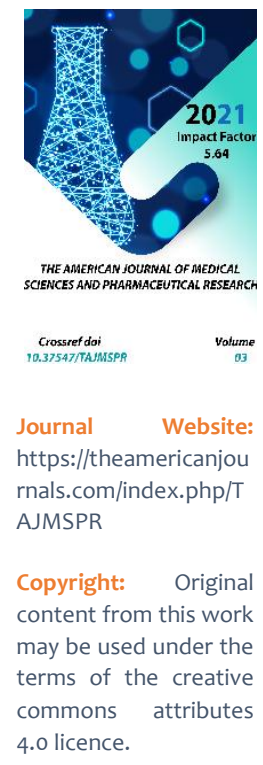

\section{Extensively Drug Resistant Salmonella Enterica Serovar Typhi Misdiagnosis In Pakistan: A Matter Of Serious Concern}

\author{
Umar Saeed \\ Department of Research and Development, Islamabad Diagnostic Center (IDC), F8 Markaz \\ Islamabad (44000), Pakistan \\ Sara Rizwan Uppal \\ Department of Research and Development, Islamabad Diagnostic Center (IDC), F8 Markaz \\ Islamabad (44000), Pakistan \\ Zahra Zahid Piracha \\ Department of Research and Development, Islamabad Diagnostic Center (IDC), F8 Markaz \\ Islamabad (44000), Pakistan \\ Rizwan Uppal \\ Principal Investigator, Department of Research and Development, Islamabad Diagnostic Center \\ (IDC), F8 Markaz Islamabad (44000), Pakistan
}

\title{
ABSTRACT
}

There have been several outbreaks of antimicrobial resistant (AMR) strains of Salmonella enterica serovar Typhi that cause extensively drug resistant (XDR) typhoid fever in Pakistan. It has been observed that many clinicians use serological diagnostic tests such as Widal agglutination, and TyphiDOT that detects IgM and IgG antibodies against the outer membrane protein of S. Typhi. However, it has been confirmed by many scientists that these test may lead to misdiagnosis against XDR S. Typhi. Due to lack of implementation strategies health authorities are unable to hamper Widal or TyphiDOT tests which are still practiced in many rural and urban areas.

\section{KEYWORDS}

S. Typhi, XDR, Widal or TyphiDOT, Pakistan

\section{INTRODUCTION}

In Pakistan, since 2016 there have been several outbreaks of antimicrobial resistant (AMR) strains of Salmonella enterica serovar Typhi (S. Typhi) belonging to the $\mathrm{H} 58$ haplotype, that cause extensively drug resistant (XDR) typhoid fever (1). Some of the $\mathrm{H}_{5} 8$ strains are resistant to chloramphenicol, ampicillin, and trimethoprim-sulfamethoxazole antibiotics (2). Fluoroquinolones and ceftriaxone have also shown resistance to S. Typhi (3). While, only azithromycin antibiotic have shown significant responses for treatment of XDR S. Typhi. The positive serological tests such as Widal agglutination, and TyphiDOT that detects IgM 
and IgG antibodies against the outer membrane protein of $\mathrm{S}$. Typhi are not recommended for diagnosis of typhoid fever $(4,5)$. There has been excessive usage of azithromycin during COVID-19 pandemic which may turn into havoc if azithromycin resistance strain appeared in near future (6).

Recently, several studies questioned the authenticity of rapid diagnostic testing kits in Pakistan. Specifically diagnosis of XDR typhoid fever caused by XDR S. Typhi, is the matter of serious concern (7,8). Pathogenic microorganisms are increasing day by day due to lack of appropriate knowledge and awareness among general populations (9-14). In Pakistan, across several rural areas of Punjab, Sindh, Balochistan, and KPK, the Widal and TyphiDOT are still being used as diagnostic tests by less qualified clinical laboratories which results into misdiagnosis of the typhoid. The Widal and TyphiDOT tests should be discontinued as there is no use of these tests and merely wastage of time and resources for accurate diagnosis against XDR S. Typhi. The blood culture is gold standard test for typhoid diagnosis and it confirmed before starting antibiotics. In other words the gold standard method is more reliable for determining XDR S. Typhi in subjects. The Government of Pakistan public sector National Institute of Health has also directed to stop forth with from conducting Widal and TyphiDOT tests for diagnosis of typhoid fever $(15,16)$. Among 241 patients positive for salmonella, TUBEX®TF was positive in $42.64 \%$ of subjects, however Widal was positive among $36.76 \%$ of the patients, with low sensitivity and specificity (17). Several non-government organizations of Pakistan should also put join efforts to implement water purification and sanitation activities, at both urban and rural community levels for health safety. Several awareness campaigns on safe hygiene and sanitation practices should be initiated in schools, colleges and universities. The government should ensure safe mass vaccination campaign (using Vi-polysaccharide typhoid vaccine or the typhoid conjugate vaccine) by creating national XDR S. Typhi taskforce to combat prevalence of multidrug resistant S. Typhi in Pakistan.

\section{REFERENCES}

1. World Health Organization Typhoid fever - Islamic Republic of Pakistan (2018). Available from: https://www.who.int/csr/don/27december-2018-typhoid-pakistan/en/.

2. Zoe A Dyson, Elizabeth J Klemm, Sophie Palmer, Gordon Dougan (2019). Antibiotic Resistance and Typhoid. Clinical Infectious Diseases, 68(2):165S170.

3. Qureshi S, Naveed AB, Yousafzai MT, Ahmad K, Ansari S, Lohana H, Mukhtar A, Qamar FN. Response of extensively drug resistant Salmonella Typhi to treatment with meropenem and azithromycin, in Pakistan (2020). PLoS Negl Trop Dis, 14(10):e0008682.

4. Taiwo SS, Fadiora SO, Oparinde DP, Olowe OA. Widal agglutination titres in the diagnosis of typhoid fever. West Afr J Med. 2007 Apr-Jun;26(2):97-101. PMID: 17939308.

5. Ismail A. New advances in the diagnosis of typhoid and detection of typhoid carriers. Malays J Med Sci. 2000;7(2):38.

6. Saeed U, Rizwan Uppal S, Zahid Piracha Z, Uppal R (2021). Azithromycin 
Treatment for SARS-CoV-2-related COVID-19 Pandemic Could Worsen Extensively Drug Resistant (XDR) Typhoid: A Risk of Losing the Last Bullet Against Salmonella enterica Serovar Typhi. Jundishapur J Microbiol, 14(1):e113874.

7. Saeed U, Uppal SR, Piracha ZZ, Rasheed A, Aftab Z, Zaheer H, Uppal R (2021). Evaluation of SARS-CoV-2 antigen-based rapid diagnostic kits in Pakistan: formulation of COVID-19 national testing strategy. Virol J, 18(1):34.

8. Saeed U, Uppal, SR, Piracha ZZ, Khan AA, Rasheed A, Zaheer $\mathrm{H}$, Aftab Z, Uppal R (2021). Effectivity Analysis of SARS-CoV-2 Nasopharyngeal Swab Rapid Testing Kits in Pakistan: A Scenario of Inadequate COVID-19 Diagnosis. Available from : https://www.researchsquare.com/artic le/rs-315851/v1

9. Saeed U, Uppal SR, Piracha ZZ, Uppal R. COVID-19 Transmission via Fomites at Low Temperature: A Potential Silent SARS-CoV-2 Propagation Route (2021). Am J Biomed Sci Res,12(1). AJBSR.MS.ID.001716.

10. Saeed U, Waheed $Y$, Ashraf $M$, Waheed $U$, Anjum S, Afzal MS (2015). Estimation of Hepatitis B Virus, Hepatitis C Virus, and Different Clinical Parameters in the ThalassemicPopulation of Capital Twin Cities of Pakistan. Virology: Research and Treatment, 6:11-16.

11. Saeed U, Waheed $Y$, Ashraf M (2014). Hepatitis B and hepatitis C viruses: a review of viral genomes, viral induced host immune responses, genotypic distributions and worldwide epidemiology. Asian Pac J Trop Dis,4(2):88-96.

12. Saeed U, Mazoor S, Jalal N, Piracha ZZ (2014). Contemplating the Importance of Toll-like Receptors I and II Regarding Human Viral Pathogenesis. Jundishapur J Microbiol, 8(1):e13348.

13. Saeed $U$, Waheed $Y$, Manzoor S, Ashraf $M$ (2013). Identification of novel silent HIV propagation routes in Pakistan. World Journal of Virology,2(3):136-138.

14. Saeed U, Manzoor S (2014). Risk Factors Associated with Transmission of Hepatitis B and Hepatitis C Virus in Pakistan. Global Journal of Medical research, 14(1):15-19.

15. National Institute of Health Islamabad Pakistan (2020). Advisory for prevention and treatment of XDR typhoid 2020. Available from: https://www.nih.org.pk/wpcontent/uploads/2020/07/Advisory-forPrevention-and-Treatment-of-TyphoidFever-including-XDR-Typhoid.pdf.

16. Centers for Disease Control and Prevention (CDC), Travel-Related Infectious Diseases: Chapter 4. Typhoid and Paratyphoid fever (2020). Available from : https://wwwnc.cdc.gov/travel/yellowb ook/2020/travel-related-infectiousdiseases/typhoid-and-paratyphoidfever.

17. Khan KA, Qureshi SU, Ehtisham S. Comparison of the performance of Tubex ${ }^{\circledR}$ TF, widal immunodiagnostic assay and blood culture in diagnosis of enteric fever in a private tertiary care hospital Peshawar, Pakistan. J Pak Med Assoc ,71(3)909-911. 